\title{
LA SENECTUD POÉTICA DE CONCHA LAGOS, MARÍA VICTORIA ATENCIA Y JULIA UCEDA A LA LUZ DE LA EXISTENCIA
}

\author{
Ana Palomo Ortega \\ Universidad de Córdoba \\ palomoortega.ana@gmail.com
}

\begin{abstract}
RESUMEN: Este trabajo de investigación se centra en el análisis conjunto de motivos religiosos y filosóficos en las últimas obras de tres poetas del medio siglo: Concha Lagos, María Victoria Atencia y Julia Uceda. En el cuerpo argumental se analizarán los principales asuntos poéticos relacionados con el ser, la existencia y el estar en el mundo de estas tres poetas a partir del estudio de Últimas canciones (1996) de Concha Lagos, El umbral (2011) de María Victoria Atencia y Escritos en la corteza de los árboles (2013) de Julia Uceda, a fin de corroborar que sus poéticas tienen como base unos fuertes cimientos existencialistas y que entre las tres autoras hay conexiones que se prueban a través de los textos.
\end{abstract}

PALABRAS CLAVE: intertextualidad, existencia, poesía, mujer, palabra.

\section{THE POETIC SENECTITUDE OF CONCHA LAGOS, MARÍA VICTORIA ATENCIA AND JULIA UCEDA IN THE LIGHT OF EXISTENCE}

ABSTRACT: This research focuses on the combined analysis of religious and philosophical reasons in the last works of three half a century poetess: Concha Lagos, María Victoria Atencia and Julia Uceda. The body argument will analyse the main poetic issues related to existence in the world of these poetess from the study of Últimas Canciones (1996) by Concha Lagos, El umbral (2011) by María Victoria Atencia and Escritos en la corteza de los árboles (2013) by Julia Uceda, with the aim of confirming that their poetics have strong existentialist foundations as a base, and there are connections between the three authors that can be proved through their texts.

KEYWORDS: intertextuality, existence, poetry, woman, word.

\section{BREVE ESTADO DE LA CUESTIÓN}

Las poéticas de Concha Lagos, María Victoria Atencia y Julia Uceda forman parte de un conjunto de obras que se han visto postergadas hasta bien entrado el siglo XXI debido, fundamentalmente, al hecho de que han sido escritas por una mujer. La crítica reciente no cesa en su empeño por recuperar toda la cultura literaria soterrada y esta es una de las tareas esenciales de la presente investigación cuyo objetivo fundamental se centra en el análisis de las claves existenciales y fundamentos filosóficos que están en la base de las poéticas de tres escritoras andaluzas del medio siglo. Dichas claves existenciales difieren entre las tres autoras. La obra de Concha Lagos puede vincularse a la línea del existencialismo cristiano, en especial tendría ecos de los planteamientos de Marcel, sobre todo de su «Filosofía de la esperanza» (Urdánoz, 1978: 736), además, en la obra de la poeta que estudiamos se prueba la importancia de la influencia de la Sagrada Escritura, a través de la conexión con obras de la tradición 
literaria que tienen como base algún libro de la Biblia. Por otro lado, en el caso de Atencia, la trascendencia de su obra viene dada por la resonancia en sus versos de la poesía mística, en especial, de la obra de San Juan de la Cruz. Por último, en el caso de Uceda, la línea existencialista que sigue -pese a que hay muchas más influencias en su última obra, tal y como se estudia en este trabajo-, es el existencialismo de Heidegger el que se descubre en sus composiciones. El filósofo alemán teoriza sobre el lenguaje literario, tal y como refiere Urdánoz: «Heidegger mantiene, pues, que el lenguaje literario, sobre todo el lenguaje poético, es un modo original de expresar el pensamiento esencial, la experiencia original de la verdad del ser que tan afanosamente indaga» (1978: 565). La obra de Uceda se encuentra directamente relacionada con estos planteamientos y en algunos de sus poemas asistimos a la búsqueda del sentido último de la existencia a través de la creación poética.

Por otro lado, hemos de atender a la importancia de la intertextualidad, sobre la que teoriza Iván Villalobos Alpízar, que para Julia Kristeva consiste en que «todo texto se construye como mosaico de citas, todo texto es absorción y transformación de otro texto» (en Villalobos Alpízar, 2003: 141). ${ }^{1}$

Partiendo de estos planteamientos iniciales, en este artículo se entrelazan las conexiones intertextuales presentes en las tres obras, así como los motivos existenciales, religiosos y/o filosóficos que impregnan la última obra de Lagos, Atencia y Uceda. Los motivos a los que hacemos mención deben tenerse en cuenta para la concepción literaria e ideológica de estas autoras porque cierran tres de los corpus poéticos más relevantes de la literatura española de la segunda mitad del siglo XX. Además, a través de su análisis se podrá apreciar la evolución de la perspectiva existencial en cada una de las poéticas individualmente y en conjunto probando, de este modo, la relevancia de este asunto en el conjunto de sus obras.

Los poemarios objeto de estudio son: Últimas canciones (1996) de Concha Lagos, El umbral (2011) de María Victoria Atencia y Escritos en la corteza de los árboles (2013) de Julia Uceda.

\section{INFLUENCIAS E INTERTEXTUALIDAD}

Comenzando por Últimas canciones (1996) la obra consta de un total de cincuenta y un poemas divididos en tres secciones. La primera, titulada «I. A la deriva» está integrada por veinticinco poemas, la segunda, «II. El anillo de fuego», incluye trece poemas y la tercera, «III. A la canción por la orilla» engloba, al igual que la segunda, trece composiciones. Llama la atención que cada una de las partes está introducida por una cita en la que ya se advierte que el correlato de la existencia se situará en la base del poemario. En cuanto a El umbral (2011), la obra de Atencia consta de veinte poemas en los que se observa cómo los motivos religiosos, en la línea de la mística, son muy relevantes. Por último, Escritos en la corteza de los árboles (2013) está integrada por veintiocho composiciones en una única sección en la que desde el título se anuncia la pervivencia de una literatura anterior o primitiva en sus versos, consideración que será de ayuda al abordar el estudio del poemario.

\footnotetext{
${ }^{1}$ La cita está tomada del artículo de Iván Villalobos Alpízar cuya referencia completa está en el listado bibliográfico final. Está extraída de Kristeva (1997), «Bajtín, la palabra, el diálogo y la novela», en D. Navarro (Traducción y selección), Intertextualité, La Habana, UNEAC, Casa de las Américas.
} 
La primera obra en la que nos detenemos es la de Concha Lagos. Como frontispicio, se estima necesario destacar una afirmación de Sánchez Dueñas en relación con la recepción crítica de la obra de la poeta. En este sentido, en el artículo introductorio al volumen dedicado a la reivindicación de la obra lagosiana, Sánchez reconoce que: «A excepción del trabajo de Gómez Gil publicado en 1981 y de la antología de Emilio Miró (Lagos, 1976), la obra de Concha Lagos ya sea en su faceta poética, narrativa, epistolar, teatral o cultural adolece de estudios particulares o de conjunto» (Sánchez, 2011: 42). ${ }^{2}$ A pesar de que esta consideración fue anotada en 2011, la bibliografía crítica sobre la obra de Lagos es muy limitada. ${ }^{3}$ Aún hay que recurrir a estas investigaciones iniciales sobre su concepción poética y su obra -y se dice iniciales porque en ningún caso los dos importantes estudios sobre su trabajo recogen el conjunto de su poesía por no haber finalizado la actividad poética de Lagos en el momento en el que se publican dichos estudios- para tener una base científica de la que partir.

Es por esto por lo que hay que tener en cuenta, en primer lugar, la afirmación de Gómez Gil, quien expone: «en poesía la interinfluencia es más virtud que vicio, pese a que algunos no nos repleguemos a aceptarlo» (Gómez, 2013: 188). Sin duda esta virtud es manifiesta en la última obra de Lagos, tanto en los metros como en los temas que aborda. En cuanto a la métrica, el poemario está conformado prácticamente en su totalidad por canciones, tal como se anuncia en el título. ${ }^{4}$ Las composiciones son piezas de arte menor inspiradas en la tradición popular andaluza con reminiscencias a los poetas del grupo del 27. A este respecto en la clasificación de metros de Gómez Gil aunque en esta ocasión en su tesis doctoral- señala que en la obra de Lagos se deben tener en cuenta tres tendencias métricas: «1) Tendencia clásica; 2) Tendencia Popular; y 3) Tendencia al cultivo moderno y amétrico» (Gómez, 1981: 168). Sin lugar a duda, la obra se adscribe a la segunda de las tendencias propuestas por Gómez Gil, además de que un poco más adelante notifica que Lagos, que había reconocido la influencia Cernuda en sus versos en distintas ocasiones, no se dejaría influenciar solo por el poeta sevillano. Así lo recoge Gómez:

Tendencia popular. Al igual que la «Generación del 27» tres son los rasgos que aproximan a la mayoría de sus componentes: El cultivo del verso libre, el de los metros populares y la inclusión básica de la canción o romance, citas o estribillos de ellos como parte del poema. [...] Y es esta tendencia a lo popular lo que hace que la obra lagosiana se incline en multitud de ocasiones hacia la copla y la canción desparramándose desde su raíz andaluza hasta las más altas ramas de su depurado estilo (1981: 169).

Siguiendo las consideraciones anteriores se aprecia cómo la última obra de Lagos se adhiere a la perfección a la métrica propuesta, pues para ella la canción popular se sitúa como fundamento de su base lírica. No obstante, antes de hablar de las posibles influencias que de la Generación del 27 encontramos en esta obra, hay que

${ }^{2}$ En la última década han aparecido otros estudios que actualizan la investigación sobre su obra poética, tal es el caso de la tesis de María Luisa Gómez Artal: Los motivos literarios en la obra de Concha Lagos y del trabajo de Blas Sánchez Dueñas y María José Porro Herrera del año 2015, titulado Concha Lagos, agente cultural. Los Cuadernos de Ágora.

${ }^{3}$ Recientemente se ha publicado en el Centro Virtual Cervantes un monográfico dedicado a Concha Lagos, comisariado por Blas Sánchez Dueñas (2021b).

${ }^{4}$ Destaca en relación con la métrica que en la tercera parte encontramos el «Romance del imposible regreso» (Lagos, 1996: 69), así como un conjunto de composiciones breves tituladas como la estrofa que emplean «Soleares» (Lagos, 1996: 70-71), ambos poemas de clara influencia lorquiana serán objeto de estudio de la presente investigación. 
remontarse a la tradición literaria española anterior para descubrir el conjunto de fuentes de las que Lagos bebe en este poemario. Es necesario reconocer que una de las principales influencias de este libro se halla en la obra de Jorge Manrique. La intertextualidad con la principal obra del poeta es más que evidente en los siguientes versos: «Por qué tendrán que ir los ríos / forzosamente a la mar, / a dejar de ser en ella / a un para siempre jamás. / Ni el llorar de tanta fuente / puede el curso desviar» (Lagos, 1996: 22). La copla comienza con una interrogación retórica que el sujeto lírico lanza al poeta castellano poniendo, de este modo, ambos textos en diálogo. La estrofa en cuestión es la tercera que, siguiendo la división tripartita de las Coplas, propuesta por Rosemarie Burkart y Anna Krause, se encuadraría dentro del primer grupo de coplas que la crítica ha aceptado cuyo tratamiento versa sobre «la fugacidad de la vida» (Pedraza y Rodríguez, 2001: 707). En ella Manrique escribe:

\author{
Nuestras vidas son los ríos \\ que van a dar en la mar \\ que es el morir: \\ allí van los señoríos \\ derechos a se acabar \\ y consumir; \\ allí los ríos caudales, \\ allí los otros medianos \\ y más chicos; \\ allegados son iguales, \\ los que viven por sus manos \\ y los ricos (Manrique, 2016: 52).
}

Sin duda la reflexión existencial situada en la base de ambos poemas hay que buscarla en un texto aún más antiguo, señalado por los estudiosos como una de las principales fuentes de la obra del poeta castellano, el Eclesiastés. ${ }^{5}$ Esta correspondencia intertextual entre la obra de Lagos y una de las grandes elegías de la Literatura Española pone de manifiesto la importancia de la vertiente existencial en la última obra de la poeta en la que los temas de la vida y la muerte son el eje central de su lírica de acuerdo con lo que afirma Ana María Fagundo: «Saberse ser para el inexorable y devastador paso del tiempo y, en suma, ser para el misterio de la muerte, es un martilleo continuo que se oye a través de toda su poesía» (2011: 103).

No son estos los únicos poemas de ambas obras que se encuentran relacionados. En versos como: «Tan de paso es el vivir / que ni la pena nos vale / pensar en lo de morir. / Y menos, ver el afán, / del que acumulando sigue / lo que aquí se va a quedar» (Lagos, 1996: 31) resuena el eco de otra de las coplas de Manrique, la VII:
Ved de cuán poco valor
son las cosas tras que andamos
y corremos,
que, en este mundo traidor,
aún primero que muramos

${ }^{5}$ Dentro del apartado del Eclesiastés titulado «La muerte» se encuentra la base existencial de ambos poemas. Atiéndase a los siguientes versos: «Todo tiene su momento, y cada cosa / su tiempo bajo el cielo: / Su tiempo el nacer, / y su tiempo el morir [...] ¿Qué gana el que trabaja con fatiga? [...] Todos caminan hacia una misma meta; / todos han salido del polvo / y todos vuelven al polvo» (Qo. 3, 1-2a. 9.20). 
las perdemos;

de ellas deshace la edad,

de ellas casos desastrados

que acaecen,

de ellas, por su calidad,

en los más altos estados

desfallecen (Manrique, 2016: 56).

En las dos composiciones se pone de manifiesto que la lucha afanosa del ser humano por permanecer, por ser en el mundo, no es más que un lastre que le impide vivir una vida plena disfrutando del presente. El sujeto lírico del poema de Lagos profiere con simplicidad una sentencia firme e inequívoca, que lleva al lector del siglo XXI a una identificación sin esfuerzo pues el tema que trata no puede ser más actual. De acuerdo con Gómez Gil, quien cita las palabras de López Rueda en relación con la poesía de Lagos, hay que reconocer que: «Advertimos en ella una preocupación obsesiva por la temporalidad. Se ve que el alma de la escritora está chocando constantemente con su límite, desgarrándose contra el muro de la muerte esas alas espirituales de que nos habla en sus poesías» (1981: 166).

Las referencias relacionadas con el tiempo son muy recurrentes en esta obra de Lagos aunque, no obstante, la perspectiva con la que se aborda este asunto es distinta según la composición. En versos como los siguientes se aprecia la actitud cambiante del sujeto lírico respecto a los poemas anteriores en los que se encontraba un atisbo de esperanza en el yo poético propio de la religiosidad. Sin embargo, en los que siguen, el yo poético muestra su desaliento tras tomar conciencia del devenir de las horas:

Yo no sé quién inventó

nuestro inútil cavilar.

Como el agua de los ríos

su indiferente pasar.

Sólo nostalgia nos deja.

La duda, de su verdad.

Si sumara las jornadas

de trabajo y agonía.

En el olvido las dejo,

como una tierra baldía.

Por las pocas de ilusión,

acaso yo volvería

bien ceñida por tus brazos,

o por sentir tu alegría

de ver correr los arroyos

tan seguros de su orilla (Lagos, 1996: 30).

Por otro lado, otra importante referencia intertextual considerable en este poemario es la de Federico García Lorca ${ }^{6}$ Como sabemos, la misma Concha Lagos reconoció la influencia del 27 y, más concretamente, de Cernuda en su obra, no

\footnotetext{
${ }^{6}$ En el apartado dedicado a los motivos existenciales se estudiará la presencia de determinados símbolos cruciales en la obra de Lagos que evocan la obra de Lorca (la pena, el agua, la noche...).
} 
obstante, las alusiones al poeta granadino aún no han sido estudiadas en profundidad ${ }^{7} \mathrm{y}$ son más que evidentes en el libro. ${ }^{8}$ En este sentido, se deben resaltar composiciones incluidas en la tercera parte del poemario, tales como el «Romance del imposible regreso» en el que el sujeto lírico reconoce la imposibilidad, anunciada desde el mismo título, de volver a Córdoba para poder morir allí. El poema se erige como prolepsis premonitoria de su devenir existencial, es un canto de despedida a su Córdoba natal, recuérdese que la poeta moriría años más tarde en Madrid en el Hospital de las Rozas. ${ }^{9}$ Al trazar esta línea intertextual habría que acotar las composiciones de Lorca en las que aparece el río Guadalquivir, cuya significación cobra tal importancia que parece tratarse más de un personaje que de un lugar, algo que se observa en poemas como la «Baladilla de los tres ríos» (Lorca, 2015: 128). En este sentido, en la obra de Lagos aparece el río como motivo poético en numerosas ocasiones, algunas ya mencionadas en el estudio de la influencia de Manrique en la poesía de la autora. No obstante, es muy significativa esta conexión entre Lorca y Lagos porque será en el poema que cierra el libro, titulado «Colofón» en el que el sujeto lírico parezca revelar el río al que se venía refiriendo desde las primeras páginas. Véase la última estrofa, así como los dos versos que cierran el poema en los que el sujeto lírico exclama la sentencia:
Hay un río en nuestra vida
que nos orilla y nos lleva.
Mil veces le he preguntado
el porqué de rumbo y meta.
Silencioso, hacia la mar,
a dejar de ser en ella
el río sigue su curso
bajo la luz o la niebla.

¡Ay, río Guadalquivir,

qué cerca ya la respuesta! (Lagos, 1996: 73).

El poema tiene un claro tono existencial y reflexivo sobre el sentido de la vida y, si bien es cierto que aparece el río Guadalquivir al final con la importancia que reconocía que tenía en la obra de Lorca,${ }^{10}$ se debe tener en cuenta que su aparición está

${ }^{7}$ Aunque María Luisa Gómez Artal dedica un apartado a la búsqueda de intertextos en la obra de Lagos que permitan ponerla en relación con la obra de Lorca, no se analiza ninguno de los poemas ni de los rasgos estudiados en este artículo (2014: 268-269).

${ }^{8}$ No se debe obviar que la influencia de Lorca en la obra de Lagos se traza gracias al neopopularismo, tan relacionado a su vez con el flamenco. A este respecto, conviene leer el artículo del flamencólogo Agustín Gómez en el monográfico dedicado a la obra de la poeta, coordinado por Sánchez Dueñas y Porro Herrera, cuya referencia está en la bibliografía final, titulado «Concha Lagos desde el flamenco», donde se examinan algunos de los poemas de la autora desde la perspectiva anotada.

${ }^{9}$ Así lo reconoce Manuel Gahete: «Me confesaba Concha Lagos, en una de las interminables charlas telefónicas que mantuvimos al final de sus días en el Hospital de las Rozas, que toda su vida había sido una contante persecución de sueños» (2021).

${ }^{10}$ Dos importantes poemas de Lorca en los que se ventilan dos acontecimientos de muerte que suceden en el río Guadalquivir. Es el caso del poema titulado «Muerte de Antoñito el Camborio», en el que desde los primeros versos aparece: «Voces de muerte sonaron / cerca del Guadalquivir» (Lorca, 2015: 263), el segundo de los versos se repite a modo de estribillo en cuatro ocasiones en el poema. Cronológicamente, la segunda de las composiciones es una de las grandes elegías de la literatura española, «Llanto por Ignacio Sánchez Mejías». Como ocurre en el poema anterior, el Guadalquivir es el espacio escogido por Lorca para el trágico desenlace del torero, que es herido de muerte en la plaza, algo 
ligada a su Córdoba natal. Siguiendo esta interpretación puede ponerse en relación este poema de Lagos con la «Canción del jinete» en la que el yo poético de Lorca exclama: «Aunque sepa los caminos / yo nunca llegaré a Córdoba» (Lorca, 2015: 204). Como se puede comprobar a través de este breve recorrido por la última obra de Lagos es reseñable la base existencial que se materializa en los poemas en aspectos como la preocupación por el paso del tiempo y la muerte y en el anhelo frustrado de volver a su tierra natal, todo ello unido a la tradición neopopular, son la clave para el estudio de Últimas canciones.

En relación con la última obra de María Victoria Atencia, El umbral, son pertinentes unas palabras de Biruté Ciplijauskaité acerca de su estructura formal:

La experimentación formal no es uno de los propósitos principales de Atencia. Maneja con gran maestría el alejandrino blanco que ha escogido como su santo y seña y cuya amplia andadura permite innumerables variaciones rítmicas dentro de la misma medida. No quiere llamar la atención hacia la hechura del poema. La búsqueda de las esencias es siempre su preocupación primaria (2004: 271).

Esta idea, uno de los rasgos definitorios de la poética de la autora, proporciona una clave esencial para profundizar en las influencias e intertextos presentes en el poemario, entre las que destaca la presencia de la mística española, en especial, en la obra de San Juan de la Cruz, tal y como ocurría en obras anteriores. ${ }^{11}$ En este sentido, en el apartado dedicado al estudio de los motivos poéticos existenciales más recurrentes en la última obra de cada una de las poetas, se analiza la terminología de claro eco espiritual en la que la huella del poeta es sutil, pues la asimilación que Atencia hace de la poesía del místico dificulta hallar los vestigios intertextuales, ${ }^{12}$ algo que la escritora consigue en este último libro, donde su universo poético llega a su cénit. En él se amalgaman con gran maestría tanto la influencia mencionada como los intertextos y referencias tomadas de otras artes y disciplinas que la han acompañado a lo largo de su obra. ${ }^{13}$ Se aprecia esto en poemas como el titulado «Qué puedo hacer sino inventarte»:

QUÉ puedo hacer en lo que va de instante

de un tiempo sucedido y ya hueco de ti,

si es que te tuvo; corazón, qué puedo

hacer sino inventarte, alto tallo de luz

que me haga a tu medida y tu abandono,

mi dormición final, mi aliento frío (Atencia, 2011:39).

que vemos en versos como: «Y su sangre ya viene cantando [...] para formar un charco de agonía / junto al Guadalquivir de las estrellas» (García Lorca, 2015: 355).

${ }^{11}$ Es obligatorio destacar que el análisis de la obra atenciana desde una perspectiva mística y religiosa se encuentra amparado en estudios de críticos como Ruiz Noguera (2016) o Ciplijauskaité (2004). Las referencias a los artículos concretos en los que pueden leerse sus consideraciones con respecto al tema objeto de estudio se recogen en la bibliografía final.

12 De acuerdo con las distintas formas de intertextualidad planteadas por Gemma Gorga, apoyando sus consideraciones en las del resto de críticos en la materia, la obra de Atencia se encontraría en «el grado máximo de influencia», que consistiría «no en la manipulación textual, sino en la absorción e incorporación de la obra ajena al propio universo creador» (Gorga, 2008: 85).

${ }^{13}$ A este respecto conviene leer el reciente artículo de Blas Sánchez Dueñas (2021a) dedicado al estudio de la importancia de los sentidos en la poética de Atencia, así como al análisis de la influencia de materias como la fotografía en su obra. 
La atmósfera en que se desarrolla la acción recreada por el sujeto lírico es propia del decir místico atenciano. El sentido último de este poema es el ansia de alcanzar «el alto tallo de luz», motivo fundamental en su obra, que permita al yo poético la transformación y el total abandono de sí mismo. Este poema guarda relación con otro titulado «Tu imposible jardín» en el que el sentir del sujeto lírico es el mismo que en el anterior:

Y cómo he de nombrarte, hallazgo mío, para hacerme tu causa, tu imposible jardín

y luz en que te mires, si me tienes el alma

desgajada de ti como otra cosa tuya a la que dispusieses

de rodillas y cara a la pared, tú, fulgor de ese instante

en que fueses haciéndome y rehaciendo

y comenzando a alzarme

desde esta nada en la que yo te invento (Atencia, 2011: 39).

Cabe destacar que de ambas composiciones sería posible hacer una lectura amorosa; no obstante, quizás sea más acertado afirmar que es precisamente el hecho de recurrir al lenguaje amoroso para explicar lo inefable, procedimiento llevado a cabo por los místicos para poder expresar la entrega total del alma a Dios, ${ }^{14}$ donde residiría la influencia sanjuanista. En ambos poemas este lenguaje es tomado por Atencia para explicar la aventura que supone la búsqueda del conocimiento intelectual pleno. La siguiente reflexión de Ciplijauskaité refleja la esencia poética de la obra atenciana y, en especial, de este último poemario, ${ }^{15}$ de ahí que se dé en ella la asimilación y transformación del lenguaje místico en forma de expresión adecuada para transmitir la necesidad de ascensión intelectual personal: «María Victoria Atencia se sitúa perfectamente dentro de esta exigencia; funda y defiende un mundo totalmente suyo que va revelando su más íntimo ser» (Ciplijauskaité, 2004: 267).

Por último, con respecto a Escritos en la corteza de los árboles (2013) de Julia Uceda, hablar sobre la estructura formal resulta complicado. Casi nada se ha teorizado acerca de la disposición métrica de este poemario, al igual que ocurre con su contenido. La bibliografía es prácticamente inexistente. Para adentrarnos en la interpretación de esta última obra debemos centrarnos en la profundidad de la palabra de cada poema para saber leer entre líneas lo que también a la poeta se le presenta de forma oculta. Sobre la estructura métrica, explica con acierto Uceda el porqué del versolibrismo presente en sus composiciones en esta y otras obras:

Los sueños no caben en estructuras métricas sin sufrir una mutilación. Las formas cerradas imponen rigidez, y el sueño, pasado a corsés verbales o escritos, de una experiencia libre, emocional, cuya naturaleza no solemos estar en situación de conocer, se convierte en cuerpo rígido, inflexible. Su forma debe tener la misma libertad y los mismos bordes que el sueño mismo. Si no lo hacemos así, creo que habremos manipulado nuestra propia alma (Uceda, 2013: 25).

${ }^{14}$ En poemas como «Las palomas» (Atencia 2011: 11) o «Más luz que tú» (Atencia, 2011: 45) el lenguaje místico que utiliza Atencia es similar al de San Juan de la Cruz y, a pesar de que podría tratarse de poemas amorosos, la forma como expresa este sentimiento permite afirmar que tras los versos hay toda una experiencia mística.

${ }^{15}$ Ciplijauskaité basa esta consideración en la afirmación de Heidegger sobre lo que significa que una obra de arte sea auténtica, para lo que debe «fundar un mundo». 
La explicación no puede ser más precisa frente a la imprecisión que supone la experiencia poética que Uceda relaciona con la experiencia onírica. El poema brota como un sueño en el que hay elementos relevantes que se presentan al despertar, mientras que otros quedan ocultos a la espera de que en otro tiempo haya palabras capaces de hacerlos emerger. Todas estas ideas explican el hecho de que la obra de Uceda carezca de estructura métrica regular u ortodoxa, alejando sus composiciones del encasillamiento dentro de los parámetros tradicionales. María Teresa Navarrete afirma que «Escritos se compone exclusivamente de silvas» (2015: 443); aunque es cierto que hay alguna silva, predomina el verso libre. Esta sería, por tanto, una diferencia fundamental entre la última obra de la poeta respecto a la obra de Lagos, una de cuyas fuentes fundamentales consistía en la presentación formal de la obra.

Por otro lado, en cuanto a la intertextualidad y las influencias presentes en Escritos en la corteza de los árboles (2013), debemos tener en cuenta que ella misma reconoce, en este sentido, que la tradición que le ha marcado no ha sido solo la literaria, sino que en su obra confluye todo aquello que ha vivido, de ahí que sus lecturas y experiencias sean consideradas por ella muy relevantes y traducibles en poesía. ${ }^{16}$ Es fundamental esta idea porque induce a buscar dichas influencias e intertextualidades presentes en el poemario no solo en la tradición literaria, filosófica o religiosa occidental, sino que la indagación debe ser mucho más amplia. En su obra convergen, además de experiencias personales y lecturas, referencias filosóficas, religiosas y culturales de naturalezas muy distintas, algo sobre lo que se debe teorizar, pues ni la propia autora es consciente de cómo aparecen en sus composiciones. Pese a todo, sí que intenta dar Uceda una explicación sobre lo que ha pretendido ser el conjunto de poemas que integra Escritos en la corteza de los árboles:

Pretendo comprender lo que solo fue un esfuerzo ciego en un ser pretérito por establecer una comunicación con su propio y primitivo yo; también demostrar la convicción de que el sentido de las palabras no se completa si no se le puede analizar desde el punto de vista hermenéutico, ya que toda alma que se expresa es sagrada. No está en mi ánimo, por lo tanto, sorprender sino reandar un camino que fue necesario descubrir para reconocernos y poseer un idioma: el paso del ruido sin sentido al sonido con sentido (Uceda, 2013: 30-31).

Todas las consideraciones anteriores centran el análisis del poemario donde se plantea ciertamente un dilema existencial. El lenguaje no es otra cosa que la posibilidad de expresarnos más allá de la dimensión individual, la facultad de plasmar con sonidos todo aquello que nos sucede, que experimentamos y que ayuda al ser humano a trascenderse. Además, como Uceda afirma es una expresión del «alma» y, por tanto, es «sagrada». El lenguaje nos ofrece la capacidad de comunicarnos con los demás, de pasar al otro y, más allá de esta capacidad, puede ser considerado como un acto de amor que posibilita al ser para ser-hacerse humano.

De acuerdo con la propia Uceda, así como con las consideraciones de María Teresa Navarrete en relación con este poemario, a pesar de que el lenguaje se sitúa en el centro de la obra, el eje sobre el que sustenta su indagación poética y que permite abordar este estudio con un orden y coherencia -no olvidemos que la propia Uceda es consciente de que pretender un orden en su obra sería coartarla- es el tiempo: «si hay

\footnotetext{
${ }^{16}$ Uceda habla sobre esto al hilo de la explicación de dos poemas de libros anteriores y los relaciona con experiencias musicales. Lo reconoce explícitamente diciendo: «es parte de mi tradición, como lo es todo lo que he vivido» (Uceda, 2013: 27).
} 
algún concepto que ha primado en la poesía de Uceda, ése ha sido el tiempo y, más concretamente, el tiempo pasado» (Navarrete, 2015: 443).

Era necesario exponer de manera introductoria todo lo anterior, pues la primera referencia que aparece en Escritos es de Madeleine Peyroux, ${ }^{17}$ concretamente un fragmento de su canción I'm all rigth entre cuyas líneas se vislumbran dos de los motivos existenciales que serán fundamentales para intentar desgranar el significado último de este poemario. Estos motivos son las lágrimas, que aparecen en poemas como «Lágrima (Formas del agua)», poema de claro tono existencial o «Bocetos», que pueden vincularse con la importancia del agua. Y, por otro lado, las cicatrices que estarían relacionadas con el título del poemario por la imagen que en sí evocan ambos, así como por lo que este motivo supone en relación con su durabilidad respecto al paso del tiempo. Es decir, la aparición de las cicatrices supone la pervivencia en el tiempo presente de algo ocurrido en el pasado, luego todo cobra sentido pues, como se viene afirmando, este poemario aborda cuestiones ya tratadas por Uceda en toda su obra anterior.

Por otro lado, tras esta cita, se sitúa otra cargada de significación. Es una traducción tomada de una colección de textos escritos en sánscrito entre el siglo VIII y el II a. C. que pertenecen a la filosofía hindú denominado Brahma Upanishad ${ }^{18}$ y recoge lo siguiente: "Al mundo de los hombres se llega por el sonido, / al de los antepasados, por los ritos, / al de los dioses, por la meditación» (Uceda, 2013: 37). Se podría plantear hasta qué punto influyó esta cita en la obra de Uceda o si más bien fue la propia autora quien decidió incluirla para introducir el poemario tras ver el resultado una vez escrito. Lo que se puede afirmar, en la línea dialéctica seguida, es que estas palabras amplían la variedad de fuentes hasta límites insospechados y hace que las influencias sean muy difíciles de escrutar. Al igual que ocurría con la referencia anterior de Peyroux, las palabras reproducidas proporcionan algunas de las claves de este poemario, la indagación sobre el ser a través del problema del lenguaje, la búsqueda del origen del ser a través de los ritos extraídos de diferentes culturas y la búsqueda de Dios por medio de la meditación que en la simbología ucediana se materializa, en muchas ocasiones, en la imposibilidad de decir, lo que lleva al sujeto lírico al silencio.

La primera composición del libro, «Kairós», llevaría a pensar en el origen del ser humano en la línea de lo que propone Sartre ${ }^{19}$ sobre la génesis de la especie. El poema recrea el dilema existencial de una niña que se pregunta de dónde viene: «¿dónde estaba yo antes de estar aquí?» (Uceda, 2013: 39). De acuerdo con estas consideraciones habría que detenerse en el título porque en él aparece una importante influencia tomada de la filosofía de la Antigua Grecia, concepto después adquirido, matizando su significado,

${ }^{17}$ Madeleine Peyroux es una cantante de jazz estadounidense cuya trayectoria vital fue difícil. Habría que resaltar que Uceda introduzca su hasta ahora último poemario con una cita de su canción I'm all right, no solo por las palabras que se reproducen, analizadas en el cuerpo del texto, sino por lo que supone en relación con la variedad de influencias presentes en esta obra según se ha podido comprobar en las palabras con las que comienza su estudio. En cuanto a la interpretación que la crítica ha dado de esta cita que introduce el poemario debe leerse lo que han considerado Mercadé y Navarrete que está recogido por esta última en su tesis doctoral (Navarrete, 2015: 450).

${ }^{18}$ Debe resaltarse que la estructura de los versos referenciados parece corresponderse con la colección de textos a las que se remite, no obstante, la cita concreta no aparece en la referencia recogida, posiblemente porque no esté traducida al español o porque parte del contenido se haya perdido en la traducción. En la bibliografía se cita una colección de textos Upanishad que han sido los que llevan a considerar la naturaleza de este fragmento.

${ }^{19} \mathrm{La}$ referencia concreta que recoge Navarrete citando a Antonio Puente e Isabel Mercadé es que para Sartre «la vida es un paréntesis entre dos nadas» (2015: 449). 
por la tradición judeocristiana. Kairós significaba en la Antigua Grecia el tiempo propicio para que ocurriera algo, en la teología cristiana refiere el momento adecuado para que Dios aparezca, ${ }^{20}$ de ahí la importancia de que sea el título de este poema. Podría interpretarse como la necesidad del ser humano de volver a la inocencia infantil para resolver la incógnita existencial ya que este sería el momento oportuno para descubrir de dónde venimos; no obstante, las interrogaciones retóricas del poema refuerzan la idea de que no hay respuesta que resuelva este dilema.

Las referencias intertextuales continúan en el poema «¿Qué se oía? (Cero)» (Uceda, 2013: 71), Uceda recoge un fragmento perteneciente al libro sagrado de los mayas, el Popol Vuh. La cita es fundamental y puede relacionarse con el momento del diluvio universal en que Dios extermina todo ser viviente de la faz de la tierra. ${ }^{21}$ Esta composición interacciona con la anterior porque remite a la necesidad del ser humano de retornar al origen último de la existencia del universo, de empezar de cero tal y como aparece en el subtítulo del poema para comprender el sentido de la realidad vital del hombre.

Mención aparte merece el poema Kadish. Ocurre lo mismo que con Kairós, el título de la composición remite a la tradición hebrea, es uno de los rezos esenciales de los judíos que constituye un panegírico a Dios, al que se le pide misericordia y redención y está escrito casi en su totalidad en arameo. De nuevo se plantean las cuestiones del habla y la desubicación existencial como ejes que vertebran su base lírica. Navarrete afirma que: «La oración y el mundo infantil se contemplan como ámbitos afines al de la palabra incorrupta. El niño de este poema representa el lenguaje prenatal, otro rasgo del origen mágico del lenguaje» (2015: 447). Destaca que aparecen distintos epítetos relacionados con Jesucristo. Así encontramos en el poema Carpintero, Niño, Dios, pequeño príncipe títulos con los que Uceda hace un recorrido por la vida del protagonista de su poema. En distintas partes, las alusiones al Mesías son más que evidentes. Comienza con unos versos en los que se pone de manifiesto, tanto el origen y nacimiento de Jesucristo, como el tiempo de vida pública en que fue recorriendo distintos lugares de Oriente Medio que se corresponde con la actual Península Arábiga. Los versos dicen así: "No hubo lugar en donde no habitara, / de donde no viniera. Lo envolvían aromas de / alturas, resplandores secretos / que más que ver se adivinaban (Uceda, 2013: 85). En relación con las influencias de este poema no es casualidad que Uceda incluya el número siete entre sus versos, pues siete fueron los lugares en los que

${ }^{20}$ En la Biblia aparece al final un índice alfabético de las notas más importantes que recoge algunos de los conceptos más relevantes repetidos a lo largo de la Escritura. Kairós se encuentra entre dichos términos y nos remite a la palabra Hora donde ambos se definen como «Tiempo señalado» (2009: 1877).

${ }^{21}$ La relación entre Popol Vuh y la Biblia ha sido estudiada por Otilia Cortez en un artículo en el que analiza importantes conexiones entre ambos textos sagrados. Este hecho es muy destacable puesto que revela que, lo que recoge Uceda en este poemario, es un dilema existencial humano que trasciende culturas y evita encasillamientos, elevándose así a la categoría de dilema universal. El fragmento de Popol Vuh ofrecido podría ser la continuación del relato bíblico del diluvio universal que dice: «Todo cuanto respira en hálito vital, todo cuanto existe en tierra firme, murió. Yavéh exterminó todo ser que había sobre la faz del suelo, desde el hombre hasta los ganados, incluidos los reptiles y las aves del cielo: todos fueron exterminados de la tierra. Sólo quedaron Noé y los que con él estaban en el arca. Las aguas inundaron la tierra por espacio de ciento cincuenta días» (Gn.7, 22-24). Se considera importante recoger estas palabras porque en el poema «Kadish» aparecerá la figura de Noé, elegido de Dios como salvaguarda de la humanidad tras el diluvio. 
transcurrió su pasión: ${ }^{22}$ «[...] Iba / o venía, quién sabe, por los siete caminos» (Uceda, 2013: 85). Termino este apartado de Uceda recogiendo que, más adelante, en la parte central del poema, hay dos versos que remiten a su innata sabiduría: $:^{23}$ «[...] Y tuvo su atarazana, su extraña habilidad / para lo no aprendido / sino arrastrado desde el lugar del que venía:» (Uceda, 2013: 85).

\section{MOTIVOS EXISTENCIALES EN LAS OBRAS OBJETO DE ESTUDIO}

Al igual que en el apartado anterior, la obra de Lagos será el punto de inicio del análisis de los motivos existenciales destacando, en primer lugar, el hecho de que algunos de los referentes que tenían más fuerza en sus primeras obras, en esta última, han sido abandonados o sustituidos. Es el caso de la figura de Dios, fundamental en sus primeros poemarios en los que la aparición del Creador era una constante. En este libro el sujeto lírico no interroga a Dios, de hecho no aparece en ninguno de los poemas, algo que llama la atención pues el dilema existencial sí que es uno de los principales asuntos de la obra y lo refleja a través de diversas muestras. De hecho, se podría afirmar que en algunos poemas se atisba la presencia de una deidad muy distinta a Dios tal y como aparecía en libros como Tema fundamental en los que se contiene una serie de composiciones donde el eco de la mística española, sobre todo de San Juan de la Cruz, se advertía en sus versos. En piezas como «Esperanza nueva» el sujeto lírico afirmaba seguro de la existencia del Creador: «Qué lejos ya su queja y qué cercano / aquel rumor de Dios, aquel consuelo» (Lagos, 1976: 110) y en estos otros versos mostraba su creencia en el cielo: "Qué sorpresa saberme a derecha y a izquierda, / a un tiempo por la tierra y a un tiempo por el aire» (Lagos, 1976: 116), mientras que el yo poético de enunciados como los siguientes se muestra desesperanzado y escéptico en relación con la posibilidad de una vida venidera mejor: «Por consolar mi tristeza / me puse a mirar al cielo. / Allí descubrí tus ojos / con el mismo desconsuelo» (Lagos, 1996: 27). Se pone de manifiesto la paradoja entre el ansia de sublimidad existencial de Tema fundamental frente al reconocimiento del sentido de la vida y el desconcertante final que espera al sujeto lírico tras su muerte. Por otro lado, es muy destacable la incredulidad con que se refiere a la bondad de Dios nombrado sutilmente a través del deíctico en los siguientes versos: «Me estoy muriendo de pena. / También de pena vivía. / De este vivir y morir / ¿quién el inventor sería?» (Lagos, 1996: 27). No es esta la única ocasión en que profiere esta interrogación retórica, unas páginas más adelante vuelve a repetir el verso, en esta ocasión culpando a Dios de haber creado el amor del que también duda que exista en plenitud, perspectiva muy distinta a como abordaba el asunto en sus primeros poemarios:

Quién el inventor sería

del desvarío.

Imposible otro invento

más sin sentido.

\footnotetext{
${ }^{22}$ En «Geografía de la Pasión de Jesús», Gonzalo Prieto (2015) recoge un conciso recorrido por los lugares por los que Jesucristo pasó durante la pasión.

${ }^{23}$ Adviértase en los versos una relación con el siguiente pasaje bíblico: «Al cabo de tres días, lo encontraron sentado en medio de los maestros, escuchándolos y haciéndoles preguntas. Todos cuantos le oían estaban estupefactos, por su inteligencia y sus respuestas» (Lc.2, 46-47).
} 
Dijiste que aquel tu amor

era fuego redivivo.

De esos amores ardientes,

la verdad, yo no me fío.

No hay llama que no se apague

cuando sopla el viento frío (Lagos, 1996: 33).

Otro motivo relevante es la pena que sustituiría a la soledad presente en sus primeras obras. Es un símbolo que debe ser relacionado también con la poética de Lorca. La crítica en su disertación sobre este asunto ha propuesto diversos estudios que la sitúan en la obra del poeta como un personaje que tiene un especial protagonismo en toda su producción. De acuerdo con Scamuzzi, este tópico está relacionado con el sentir más profundo del cante andaluz por lo que guarda relación intrínseca con la obra de Lagos: «Es justamente la presencia de la Pena, hermana de soledad y de muerte, la que García Lorca extrae de su propia alma andaluza y del canto individualísimo de los cantaores de su tierra, el elemento que hace adecuada su poesía al siglo veinte» (Scamuzzi, 2009: 90).

Por otro lado, junto a la pena, el agua cobra especial significación en este poemario. La trascendencia de este símbolo estaría relacionada con lo que afirma Cirlot:

Sus cualidades dominantes son: fertiliza, purifica, disuelve. La íntima conexión de estas condiciones permite relacionarlas de diversos modos, en los que siempre resultará un hecho: que la disolución de las formas, la carencia de formas fijas (fluidez) va ligada a las funciones de fertilización o renovación del mundo vivo, material, y de purificación o renovación del mundo espiritual (Cirlot, 1969: 74).

En la última obra de Lagos se concreta este símbolo, fundamentalmente, en el río, cuya fuerza alegórica está muy relacionada en la tradición literaria, con el tópico latino vita flumen, en la línea existencial de la obra de Manrique. Se puede apreciar que el agua es una constante poética en la obra de Lagos, a pesar de que sea tratada desde distintas perspectivas según su etapa lírica. En este sentido hay que añadir que quizás la significación existencial que cobra el símbolo en esta última obra tiene que ver con el momento vital de la autora. En su primera etapa estaba muy relacionada con el vitalismo e idealismo, como aparece en el siguiente poema de Arroyo claro (1958):

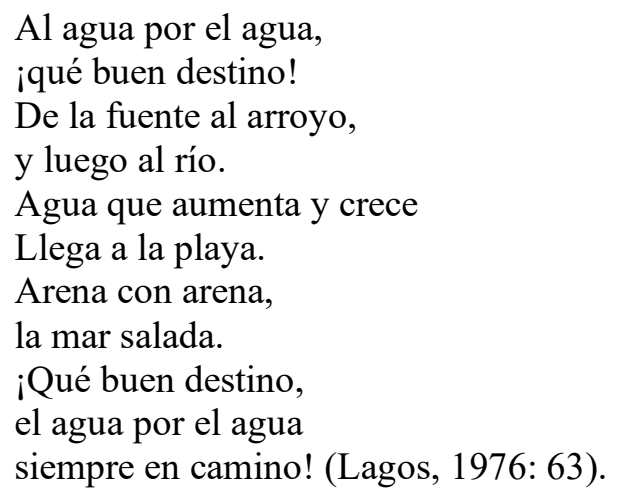

En piezas de su último poemario aparece un agua que conduce al mar, como trasunto del devenir existencial. De ella deriva otra serie de motivos, tales como la orilla o la barca, que representarían respectivamente el momento vital del sujeto poético y, 
posiblemente, el amor capaz de conducir amablemente a este hablante lírico que navega en deriva existencial hacia la muerte. Los siguientes versos de Últimas canciones lo reflejan:

\author{
Si supiera de qué fuente \\ brotó la gota primera. \\ Qué arroyo la fue llevando \\ a su destino o condena. \\ Fundida voy a su agua, \\ a ser y no ser en ella, \\ y allá por la mar salada, \\ igual meta o ruta nueva. \\ Tal vez misterio, penar, \\ o, desplegando su vela, \\ la barca otra vez, tus ojos \\ para guiarme en la niebla (Lagos, 1996: 26).
}

Otro símbolo significativo que aparece en los albores líricos de Lagos, así como en los de sus coetáneas, es el de las alas. ${ }^{24}$ En sus tanteos poéticos iniciales estaban relacionadas con las ansias de vuelo simbólico que caracterizaba a las poetas de la generación del 50, en esta obra, el mencionado vuelo simbólico que, en los casos concretos de Lagos y Atencia guardaba también una clara relación con la ascensión mística, encontramos la realidad existencial manifiesta. Relacionándolas con el futuro profiere el sujeto lírico: «¡El futuro! nube incierta / en alas de la ilusión». Y más adelante añade: «Cantar es el mejor puente / para cruzar esta vida. / Lo que arrastra la corriente / el por qué del ala herida» (Lagos, 1996: 28).

El último de los símbolos con una clara connotación existencial en Últimas canciones aparece en los dos primeros versos de la estrofa anterior. ${ }^{25}$ El tratamiento de este asunto es la mejor forma de concluir los motivos poéticos existenciales en la obra lagosiana por la profundidad de su significación. En Últimas canciones se revela, en no pocas ocasiones, la importancia de la canción y la copla desde distintas perspectivas. Se exhibe cómo cantar es algo que la ha acompañado a lo largo de su vida. La equiparación entre canción y poesía, entre cantar y escribir queda patente en: «Cantares tuve de estíos, / de primaveras en flor. / Cantares de amor, de sueños, / de alguna ardiente

${ }^{24}$ Este símbolo se relaciona con otro claramente existencial y muy significativo en las poéticas de las tres autoras, el pájaro. En la obra de Lagos aparece en bastantes ocasiones reflejando, en el caso de la aparición de la paloma, sus ansias de sublimidad existencial, de vuelo, de conocimiento, en la línea de la mística, teniendo en cuenta la importancia de este animal para la tradición judeocristiana: «donde mi paloma aquella / mensajes siembra al pasar» (Lagos, 1996: 25); «Que vuele o se crea paloma / -si esto le alivia el dolor-» (Lagos, 1996: 35). Destaca la presencia de este pájaro en un poema en que el sujeto lírico lo equipara a la creación poética: «Hay quien la llama paloma / y hay quien la llama poesía» (Lagos, 1996: 37). Y, por otro lado, aparecen otras especies, como es el caso de la golondrina o el ruiseñor, que ayudan al sujeto lírico a ejemplificar su desorientado caminar: «Desnortada por mi noche / como golondrina ciega / sin saber si voy, o vengo» (Lagos, 1996: 27); «o que sin descanso cante / como ciego ruiseñor» (Lagos, 1996: 35).

${ }^{25} \mathrm{Se}$ intuye una referencia intertextual clara entre la obra de Lagos y la de Machado porque se realiza a través del motivo estudiado. El intertexto en cuestión está tomado de Proverbios y cantares. El verso de Lagos es prácticamente el mismo que el del poeta sevillano, no obstante, la poeta da un giro de significado resaltando uno de los símbolos estudiados en este artículo. El poema de Lagos lleva por título «Donde menos se espera canta la alondra» y el verso al que me refiero dice así: ««Caminante, no hay camino». / Se hace camino al cantar» (1996: 63). La referencia directa a este poemario no es insustancial pues no debemos obviar la base bíblica y existencial de esta obra de Machado. 
pasión» (Lagos, 1996: 34). Destaca de este símbolo la idea de que escribir poesía es igual a permanecer para la historia, la escritura supone la continuidad de su recuerdo, que sería una forma de salvación frente a la finitud corporal. A este respecto Ana María Fagundo anotó: «La palabra, débilmente a veces, pero siempre fiel, es lo único que en la visión angustiada de esta poeta tiene un poder si no decididamente salvador, al menos, aliviador del vacío» (2011: 112).

En cuanto a la simbología en El umbral (2011), el principal de los motivos del poemario es el pájaro. Hemos de recordar que en obras anteriores tenía distintas interpretaciones de entre las que destacan el dolor del exiliado tras abandonar sus raíces, tal como vemos en el poema «Exilio» de El Mundo de M.V.: «Mientras los pies se hieren entre las rastrojeras / un pájaro de luto contra su tórax rómpese» (Atencia, 1978: 44).

En relación con este símbolo poético, de las veinte composiciones del último libro de Atencia cuatro de ellas llevan por título el nombre de algún ave: «Las palomas», «El ruiseñor», «Los vencejos» y «Los pájaros», además de aparecer en otros poemas en los que tienen una importante significación. En «Este hilo de vida», pórtico de la obra, se lee:
AHORA que tantas horas van quedándose atrás y olvido ya su hechura y pertenencia, vuelvo a sentirme en un aletear tras de los vidrios que empieza a deshacer la oscuridad del cielo como si, con sus plumas de poetas mayores, viniesen el petrel o el martín pescador a avisarme de que aún no ha cambiado más de lo que es preciso este hilo de vida en el que me sucedo (Atencia, 2011: 9).

Aquí se registra el paso del tiempo ligado a la experiencia poética que parece ser la vía que permite comprender el sentido de la existencia. El sujeto lírico, que en este caso sería trasunto del sentir de la propia poeta, advierte al lector de que lo único que ha cambiado es «este hilo de vida en el que me sucedo», no obstante, se observa en ella una necesidad de seguir escribiendo para alcanzar la sublimidad existencial, tras saberse suspendida en un tiempo que no se detiene pero cuyo paso no le provoca ningún desasosiego. Los pájaros cobran una relevancia especial en la composición, ya que «con sus plumas de poetas mayores» instan a la poeta a continuar con su labor. Las interpretaciones que la crítica ha dado del ave sostienen el sentido subyacente en esta composición. Según José Luis Fernández: «El pájaro es [...] un vínculo entre dos ámbitos o planos espirituales, pero un vínculo en este caso dinámico, que requiere y busca la transformación» (2008: 360), tal es el caso del poema «Los vencejos», de tono existencial, en el que la suspensión temporal invita al olvido para ceder al destino último del ser humano sin forcejeo y libre de ataduras. A su lado, la tarde en este poema se eleva como alegoría de la senectud, al igual que lo es el umbral con que Atencia titula su obra. ${ }^{26}$

\footnotetext{
${ }^{26}$ Es muy significativa esta consideración porque permite poner en relación la obra de Atencia con la de Antonio Machado. En este sentido se han de tener en cuenta las siguientes palabras: «resulta apenas discutible - por la carga de consunción vital que arrastra la propia palabra- la dimensión existencial de este uso machadiano. En efecto, las aclaraciones al respecto de los mismos eruditos («la muerte del día», «consumación del día», «otoño del día», etc.) son harto elocuentes. Resulta esta categoría, a veces, más que de mera expresión de temporalidad, de captación tácita y simultánea de angustia existencial» (Rodríguez, Rodríguez y Ruiz, 1975-1976: 694).
} 
Otro de los símbolos presentes en la obra de Atencia con especial relevancia en estas páginas es la luz. De acuerdo con José Luis Fernánde ${ }^{27}$ la base de este motivo en relación con la divinidad habría que buscarla en el prólogo al Evangelio de Juan en el que se oponen luz y tinieblas (2008: 367). En este sentido, en la obra de Atencia puede verse cómo la $l u z$ se relaciona con el descanso y el abandono que inundan el poemario. En el poema «Las palomas» se dice: «y era todo un sosiego ya atenuada la luz» (Atencia, 2011: 11); en «El ruiseñor» aparece: «sobre una tierna rama ya suspensa en la luz» (Atencia, 2011: 13). Se halla también en poemas como «Qué puedo hacer sino inventarte» $\mathrm{y}$ «Tu imposible jardín», aunque en el poema en el que el símbolo cobra más significación existencial es «Más luz que tú» en cuyos versos se enuncia:

Y yo te iba siguiendo y persiguiendo y te iba

rebañando los pasos para saber de ti,

de ti contigo ya tan dentro de tus lindes

que el sol se enmohecía y ya no había

más luz que tú, y yo iba desdiciéndome

y me iba desviviendo y deshaciéndome

y te alcanzaba donde coincidíamos (Atencia, 2011: 45).

Por otro lado, otro de los motivos existenciales fundamentales de este poemario es la palabra creadora. De acuerdo con Sharon Keefe Ugalde: ${ }^{28}$ «El proceso creativo asume un protagonismo y se hacen visibles las distintas etapas en la trayectoria ascendente hacia la palabra reveladora» (2004: 9). Esto se advierte en «La tinta, el curso azul». La palabra poética parece apoderarse del yo lírico: «La tinta, el curso azul y sus insignias, / como una vena que me recorriese y tiño, / y escribo y leo y sufro su latido» (Atencia, 2011: 47). En «Nadie» el yo poético escribe para encontrarse a sí misma y como forma de conocimiento del otro: «con el recurso azul que va enseñándome / a hablarle a tu silencio. [...]» (Atencia, 2011: 41).

En El umbral, el significado simbólico del agua adquiere el mismo sentido que en las poéticas de Lagos y Uceda, por lo que permite poner las tres obras en relación. El sentido no es otro que existencial, el sentir del paso del tiempo, de la vida que se escapa y que fluye como un río cuyo caudal es imparable. Este caudal es trasunto de la existencia humana que se sucede de manera cíclica. En los últimos versos de «De partos y relevos» se conjugan todas estas ideas:

Al agua clara puedo preguntarle quién soy:

después de tantos partos y relevos generacionales

para el mismo caudal que me enriquece ahora

y que se solivianta a veces aguardando su turno

y su ocasión, porque la vida urge y su oportunidad

no se repite. Como el rostro que sabes, sólo

una vez en mil años, llega a darse al espejo (Atencia, 2011: 33).

${ }^{27}$ José Luis Fernández expone estas consideraciones acerca de la luz como símbolo poético en la obra de Valente, no obstante, se considera que sus ideas pueden relacionarse con la obra de Atencia, pues también en la obra de Valente encontramos influencia de la mística y, concretamente, de la obra de San Juan de la Cruz como ocurre en la obra de la poeta.

${ }^{28}$ En un artículo titulado «Los grandes temas: ellas también», en el apartado que lleva por nombre: «En busca de la luz: la aventura poética», Ugalde estudia unos versos de Isla Correyero y María Antonia Ortega, cuyas ideas pueden tenerse en cuenta en el estudio de la obra de Atencia. 
Por último, en cuanto a los motivos poéticos existenciales presentes en Escritos en la corteza de los árboles (2013) de Julia Uceda, se debe partir de una afirmación de la propia poeta para quien: "La poética es una lengua que nadie habla pero los mitos y los símbolos de que se vale son en sí un idioma universal. Todos lo entienden en los distintos niveles de comprensión ya que trata de verdades eternas en todo tiempo y en toda cultura» (Uceda, 2013: 22-23). Siguiendo esta estela, el silencio emerge como motivo a lo largo de toda su poesía:

Pero el silencio en Uceda no está solo grávido de sentidos [...] es un agente represor de instintos, sentimientos y realidades [...]. Ante el coetáneo que dejó perder palabras y versos, que fueron a «parar al rincón de los desechos / con aquella pureza, con tantos ideales» («Palabras»), Uceda no siente perplejidad; bien al contrario, dando un paso más adelante, apunta a la inutilidad de las empresas humanas, en especial de las hermosas (García-Posada, 2006: 98).

El silencio en la obra de Uceda cobra especial relevancia porque se relaciona con la incapacidad de comunicación, lo que lleva al ser humano a una profunda frustración. En «Palabras y campanas» leemos: «[...] Las palabras, sonidos, / ya no dicen o ya no es necesario / decir pues su lugar lo ocupan / un vacío, un rostro extraño, / un asqueroso sin sentido» (Uceda, 2013: 65).

En los versos siguientes de «Animal miedoso» aparece la palabra manoseada, estropeada por el hombre de manera que no cumple con la función que persigue, la búsqueda del cambio. Los versos que siguen son evidencia fiel de las palabras de García-Posada, en ellos se propone al lenguaje como único medio para transformar la humanidad: «[...] palabras cuyos puños / golpean recios dientes para / lanzar un nuevo testamento» (Uceda, 2013: 51). No obstante, también a través de ellos tenemos noticia de la imposibilidad de cambio en las «empresas humanas» a que se refiere el crítico, pues el poema sentencia en su último verso:

palabras vivas, pero todas

\section{Buscan}

están chupadas, babeadas,

opacas de humedad, de testamentos.

Sospechan

que después de esa reja habrá otras rejas y al final

tal vez el agua corra por un cauce distinto.

Temen

si en ese cauce, en esa tierra no hallarán

otra reja, otra reja y otra reja y se hayan secado

las promesas, las hojas de futuro,

y nadie necesite esas palabras cuyos puños

golpean recios dientes para

lanzar un nuevo testamento.

si al final, o al principio de su espacio,

Cada uno, en solitario, se pregunta

se perderá, si encontrará la cueva

que dejó un día

y en ella, bien dispuestas, las ramas

de no sabe qué tiempo.

Recuerdan

Que en la noche giraban esferas de colores. Las estrellas 
se quedaron inmóviles mirándolos despacio.

Lo demás

era todo silencio (Uceda, 2013: 51).

Se advierte una clara influencia de las consideraciones de Heidegger sobre el lenguaje. La filosofía de este autor se sitúa en la base de la obra ucediana. Recuérdese como referencia explícita que Extraña juventud (1962), obra de su primera etapa, se abría con una cita del filósofo alemán. En este sentido habría que considerar las siguientes palabras en las que se encuentra el problema del lenguaje que Uceda recrea en estas y otras composiciones, cuyas raíces se sustentan según el filósofo en la esencia misma del ser:

Pero aun la amenaza a la esencia del hombre (die Bedrohung des Menschenwesens) a causa de la decadencia (Verfall) del lenguaje y la degradación de la palabra no puede bastar para justificar el pensar «sobre» la palabra, ya, empero, aparentemente reflexionado. Además de esto, la decadencia del lenguaje es quizá solamente una consecuencia de la amenaza a la esencia del hombre, amenaza que viene de otro origen. Ella surge del olvido del ser (Heidegger, 2015: 78).

Este problema del ser y el no-ser unido a la palabra y a la entidad que esta confiere a lo nombrado en el mundo aparece en composiciones como «Pensamiento, forma, sonido», donde las palabras se erigen en sonidos capaces de dar forma al pensamiento, algo que en ocasiones resulta imposible, de ahí que de nuevo aparezca el silencio ante la imposibilidad de comunicar lo inefable. Al igual que en "Animal miedoso» queda patente la incapacidad para expresar mediante el lenguaje aquello que siente el sujeto lírico:

No se formularon

las palabras que necesito: el pensamiento

vaga y se rebela hasta encontrar sus formas

pero no...

Solo puede

contemplar el silencio, su manto de espuma,

envolverse en un ya vendrán o

las dirá alguien

algún día. Pero no estaré ni habré dicho

lo que quise decir, pues se quedó enrollado

en su forma de bruma.

Mira las piedras por si ellas...

...y no llegan porque no pertenecen

a idioma alguno todavía, esas

palabras, hasta que algún poeta las encuentre.

¿Por qué el abismo

entre sonido y pensamiento si este

es claro, y en el lugar del corazón

y la materia que es estableció su morada? (Uceda, 2013: 67).

El símbolo que Uceda utiliza de manera novedosa en esta obra y que destaca porque no aparece en su primera etapa es el agua, motivo que conecta su poética con las de Lagos y Atencia. Además de recogerse este en el primero de los poemas analizados, sobresalen, fundamentalmente, dos composiciones tituladas: «Lágrima (Formas del 
agua)» y «Río (Formas del agua II)» sobre los que teoriza María Teresa Navarrete quien afirma: «dos momentos de una misma reflexión que queda delimitada bajo la circularidad del agua. [...] El agua aparece como la fuente del pensamiento original» (2015: 452). De acuerdo con su interpretación habría que añadir que, en sendos poemas, subyace una fuerte carga existencial. En el primero se dice: «Porque estamos de paso como si no supiéramos / Que hemos venido solo para un día o menos» (Uceda, 2013: 43). El tiempo, eje conductor de toda la poética ucediana se une a la simbología del agua, mientras que el sujeto lírico aprovecha la ocasión para advertir de la fugacidad de la existencia. De igual manera ocurre en la segunda composición en la que se relacionan pasado y futuro a través de elementos propios de la cultura tradicional:

al sonido adulto. No le pongan

No le pongan riendas

bozal a las bocas que lanzan ruidos, piedrecillas, oraciones, salmodias. Ecos

desde cuándo, hasta dónde.

Será

lo que nos conozca, lo que nos defina

y empape la lágrima

perdida en el agua de un viejo río

sin fondo, sin cauce, sin nombre

-las llaves del tiempo-

al que nadie ha ido a beber todavía (Uceda, 2013: 87).

Es fundamental el hecho de que el sujeto lírico inste a que se escuchen las palabras que emanan del pasado «sonido adulto», «piedrecillas, oraciones, salmodias» como forma de preservar el presente «lo que nos conozca, lo que nos defina» y de asegurar el futuro «-las llaves del tiempo- / al que nadie ha ido a beber todavía».

\section{CONCLUSIONES}

Como colofón recopilatorio cabe ser subrayado que el estudio de cada uno de los poemarios analizados, siguiendo la línea de la intertextualidad y las influencias, permite resaltar distintas cuestiones. En primer lugar, es muy relevante el hecho de que en cada una de las piezas el intertexto aparezca de forma diferente. En el caso de Lagos, las obras que integran su primera etapa estaban muy influenciadas por la poética de Cernuda mientras que en determinados poemarios aparecía una clara influencia de la poesía mística española, sobre todo de San Juan de la Cruz. En Últimas canciones, las cuestiones existenciales se plasman siguiendo la estela de la tradición literaria española, siendo visible la huella de Jorge Manrique, además del neopopularismo, tomado sobre todo de la poesía de Lorca. En relación con los motivos poéticos que aparecen en esta obra destaca, fundamentalmente, que las fugaces incursiones de la figura de Dios son radicalmente distintas a como aparecía el Creador en sus albores poéticos. El agua cobra especial relevancia en relación con el paso del tiempo y el devenir existencial, tal y como ocurre en la obra manriqueña y, por otro lado, al ser el neopopularismo lorquiano una de las principales fuentes de esta obra, la soledad, que se erigía como motivo poético existencial en los poemarios de influencia cernudiana, es ahora sustituida por la pena motivo esencial de la poética lorquiana. Por último, junto con el agua el motivo que se considera sustancial porque permite poner en relación las tres 
obras que estudiamos, es la pervivencia del ser a través de la palabra, en este caso de la palabra poética materializada en la canción.

En la obra de Atencia, la misma influencia que se advertía en sus primeras obras estudiadas por críticos como Ciplijauskaité, es la que guía sus composiciones. En El umbral, a pesar de que se advierte dicha influencia, la autora pone de manifiesto que la asimilación de la poética del místico, además de otras influencias, tomadas sobre todo de diversas artes y disciplinas, han contribuido a que en este último poemario sean difíciles de encontrar los vestigios intertextuales. Los principales motivos poéticos estudiados en la línea de la preocupación existencial son los pájaros, que están vinculados con la palabra poética, además de que son símbolo de cambio que permite al sujeto lírico en distintas composiciones aceptar el devenir existencial. La luz es otro de los motivos que cobra especial relevancia al relacionarse con el sosiego que provoca el abandono en el sujeto lírico. Por último, habría que subrayar el impacto de la palabra creadora, que capacita a la autora para permanecer en el tiempo y, por otro lado, del agua, que tiene las mismas connotaciones que en la obra de Lagos, resaltando la fugacidad del tiempo e insistiendo en que la vida humana es cíclica.

Por último, las influencias e intertextualidad en la obra de Uceda, Escritos en la corteza de los árboles, son de muy distinta naturaleza. Hay que poner de relieve las referencias explícitas que preceden a algunas composiciones porque proporcionan claves para poder interpretar los poemas. Uceda incluye citas de algunos de los principales libros sagrados de distintas religiones, sobre todo, del hinduismo y de la cultura maya como base paratextual semiótica que despliega significados sustantivos para la lectura exegética de sus obras. Las referencias a la tradición cristiana la lleva a cabo a través de distintos personajes bíblicos que cobran relevancia en sus poemas. Es muy significativo que en una misma obra incluya referencias culturales y religiosas de diversa índole porque pone de manifiesto que el problema existencial es algo que pertenece a todas las épocas y culturas. Uno de los principales símbolos existenciales que bañan el poemario es el silencio, que tenía mucha relevancia en su primera etapa poética simbolizando la ausencia de Dios. En este último poemario, aparece entrelazado el problema del lenguaje, y su relación con el ser, cuya influencia la encontramos en Heidegger. En este sentido, al igual que ocurre con las últimas obras de Lagos y Atencia, la palabra se sitúa en el centro de su obra como asunto existencial. El agua se muestra como motivo recurrente y, como ocurría en Últimas canciones y El umbral simboliza el paso inexorable del tiempo y la fugacidad de la existencia.

\section{OBRAS CITADAS}

Atencia, María Victoria (1978), El mundo de M. V., Madrid, Ínsula.

Atencia, María Victoria (2011), El umbral, Valencia, Pre-textos.

Biblia de Jerusalén (2009), Bilbao, Desclée de Brouwer.

Ciplijauskaité, Biruté (2004), «El compromiso alado de María Victoria Atencia», en La construcción del yo femenino en la literatura, Cádiz, Servicio de Publicaciones de la Universidad de Cádiz, pp. 265-275,

Cirlot, Juan Eduardo (1969), Diccionario de símbolos, Madrid, Ediciones Siruela.

Cortez, Otilia (2008), «Intertextualidad y paralelismo entre el Popol Vuh y la Biblia», Espéculo, 40, <https://webs.ucm.es/info/especulo/numero40/popolbi.html $>$. 
Fagundo, Ana María (2011), «Concha Lagos: semblanza y poesía», en Blas Sánchez Dueñas y M. ${ }^{a}$ José Porro Herrera (eds.), Concha Lagos en el panorama literario de su tiempo, Córdoba, Diputación Provincial de Córdoba, pp. 97-114.

Fernández Castillo, José Luis (2008), El ídolo y el vacio La crisis de la divinidad en la tradición poética moderna Octavio Paz y José Ángel Valente. Tesis doctoral, Madrid, Universidad Autónoma de Madrid.

Gahete Jurado, Manuel (2021), «La tejedora de sueños», en Blas Sánchez Dueñas (comis.), Concha Lagos, Centro Virtual Cervantes, $<$ https://cvc.cervantes.es/literatura/escritores/concha lagos/acerca/articulo 03.htm>.

García Lorca, Federico (2015), Obras completas, Madrid, Iberia Literatura.

García-Posada, Miguel (2006), «Una aventura del conocimiento», en Julia Uceda, Zona desconocida, Sevilla, Fundación José Manuel Lara, pp. 83-104.

Gómez Artal, María Luisa (2014), Los motivos literarios en la obra de Concha Lagos, Zaragoza, Servicio de Publicaciones de la Universidad de Zaragoza.

Gómez Gil, Alfredo (1981), Concha Lagos bajo el dominio de la literatura comparada, Alicante, Instituto de Estudios Alicantinos, Diputación Provincial de Alicante.

Gómez Gil, Alfredo (2011), «Testimonio lírico de una gran mujer», En Blas Sánchez Dueñas y M. ${ }^{a}$ José Porro Herrera (eds.), Concha Lagos en el panorama literario de su tiempo, Córdoba, Diputación Provincial de Córdoba, pp. 177-194.

Gómez, Agustín (2011), «Concha Lagos desde el flamenco», en Blas Sánchez Dueñas y M. ${ }^{\text {a }}$ José Porro Herrera (eds.), Concha Lagos en el panorama literario de su tiempo, Córdoba, Diputación Provincial de Córdoba, pp. 87-96.

Gorga, Gemma (2008), «Ecos sanjuanistas en la poesía última de Clara Janés», DICENDA. Cuadernos de Filología Hispánica, 26, pp. 83-100.

Heidegger, Martin (2014), «La Palabra: la Significación De La Palabra», Heidegger. Antología Filosófica, 77-80, <https://es.scribd.com/document/369372936/Heidegger-MartinAntologia-Filosofica>.

Lagos, Concha (1976), Antología (1954-1976), ed. y pról. Emilio Miró, Barcelona, Plaza \& Janés.

Lagos, Concha (1996), Últimas canciones, Córdoba, Departamento de Cultura y Educación del Ayuntamiento de Córdoba.

Machado, Antonio (2010), Proverbios y cantares, Biblioteca Virtual Universal, $<$ https://biblioteca.org.ar/libros/158144.pdf $>$.

Manrique, Jorge (2016), Coplas a la muerte de su padre, E. Godoy (edición y estudio), Santiago, Mago Editores / Colección Clásicos.

Navarrete Navarrete, María Teresa (2015), La obra literaria de Julia Uceda. Tesis doctoral, Cádiz, Universidad de Cádiz.

Pedraza Jiménez, Felipe y Milagros Rodríguez Cáceres (2001), Manual de literatura española. Edad Media, Pamplona-Iruñea, Cénlit Ediciones.

Prieto, Gonzalo (2015), "Geografía de la Pasión de Jesús», Geografía infinita (blog), $<$ https://www.geografiainfinita.com/2015/04/geografia-de-la-pasion-de-jesus/>.

Rodríguez, Luz, Alfredo Rodríguez y Tomás Ruiz (1975-1976), «El uso de “tarde” en la poesía de Antonio Machado», Cuadernos Hispanoamericanos, 304-307, 2, pp. 690-697.

Ruiz Noguera, Francisco (2016), «De la raíz al vuelo: la poesía de María Victoria Atencia», edición digital a partir de Campo de Agramante: revista de literatura 22 (primaveraverano 2015), Alicante, Biblioteca Virtual Miguel de Cervantes, pp. 61-73.

Sánchez Dueñas, Blas (2011), «Concha Lagos: actualidad y novedad desde la revisión crítica», En Blas Sánchez Dueñas y M. ${ }^{\mathrm{a}}$ José Porro Herrera (eds.), Concha Lagos en el panorama literario de su tiempo, Córdoba, Diputación Provincial de Córdoba, pp. 7-51.

Sánchez Dueñas, Blas y M. ${ }^{a}$ José Porro Herrera (2015), Concha Lagos, agente cultural. Los Cuadernos de Agora, Madrid, UNED.

Sánchez Dueñas, Blas (2021a), «El arte de la contemplación y la sensorialidad en la génesis creativa de María Victoria Atencia», Signa, 30, pp. 647-668. 
Sánchez Dueñas, Blas (comis.) (2021b), Concha Lagos, Centro Virtual Cervantes, $<$ https://cvc.cervantes.es/literatura/escritores/concha lagos/default.htm $>$.

Scamuzzi, Iole (2009), «El eterno canto de la pena: Adorno, García Lorca y el Cante jondo», Artifara. Revista de lenguas y literaturas ibéricas y latinoamericanas, 9, pp. 85-92.

Uceda, Julia (2013), Escritos en la corteza de los árboles, Sevilla, Fundación José Manuel Lara.

Ugalde, Sharon Keefe (2004), «Los grandes temas: ellas también», Zurgai: Euskal herriko olerkiaren aldizkaria: Poetas por su pueblo, mes 7 (julio), pp. 6-17.

Urdánoz, Teófilo (1978), Historia de la filosofia. Siglo XX: De Bergson al final del existencialismo, VI, Madrid, Biblioteca de Autores Cristianos.

Villalobos Alpízar, Iván (2013), «La noción de intertextualidad en Kristeva y Barthes», Revista de Filosofía de la Universidad de Costa Rica, XLI, 103, pp. 137-146. 